\title{
Cytophagic and S-100 protein immunoreactive myeloid leukemia cutis
}

Myeloid leukemia cutis (LG) is the cutaneous involvement by neoplastic leukocytes of the myeloid series. Myeloid LC may occur de novo or concurrently with acute myeloid leukemias, chronic myeloid leukemias, other myeloproliferative disorders or myelodysplastic syndromes. We describe an unusual case of cytophagic S-100 protein immunoreactive leukemia cutis presenting in an 87-year-old woman without prior history of myeloid leukemia or other hematologic disorders. We outline key histologic and immunohistochemical features that aide in the diagnosis of LC. The presence of cytophagocytosis on histologic examination, a phenomenon more commonly associated with lymphoid rather than myeloid malignancies, provided a clue to the possibility of a malignant process. The atypical myeloid infiltrate showed S- 100 protein positivity, an unusual finding that may be seen in LG. Although not commonly reported in LC, the presence of S-100 protein positivity and cytophagocytosis should not lead to the premature exclusion of LC as a possible diagnosis until a thorough clinical, histologic and immunohistochemical evaluation is performed. In addition, the presence of cytophagocytosis has been shown to have prognostic significance for patients with myeloid leukemia.

Thomas CG, Patel RM, Bergfeld WF. Cytophagic and S-100 protein immunoreactive myeloid leukemia cutis.

J Cutan Pathol 2010; 37: 390-395. (C) 2009 John Wiley \& Sons A/S.

\author{
Crystal G. Thomas ${ }^{1}$, Rajiv M. \\ Patel $^{2}$ and Wilma F. Bergfeld ${ }^{3}$ \\ ${ }^{1}$ University of Texas Southwestern Medical \\ Center, Department of Dermatology, Dallas, TX, \\ USA, \\ ${ }^{2}$ University of Michigan, Departments of \\ Pathology and Dermatology, Ann Arbor, MI, USA, \\ and \\ ${ }^{3}$ The Cleveland Clinic Foundation, Divisions of \\ Pathology and Laboratory Medicine and \\ Dermatology, Cleveland, $\mathrm{OH}$, USA
}

Wilma Bergfeld, MD, FACPCleveland Clinic Health System, 9500 Euclid Avenue, A61, Cleveland, OH 44195 Tel: (216)-444-5722

e-mail: bergfew@ccf.org

Accepted for publication March 31, 2009
Cutaneous involvement by leukemic cells, consisting of myeloblasts and myeloid cells in varying stages of differentiation, is referred to as myeloid leukemia cutis (LC). ${ }^{1}$ Most cases of myeloid LC have been observed in patients with acute myeloid leukemia (AML) or myeloproliferative disorders; however, cutaneous involvement has been reported in patients with myelodysplasia as well. ${ }^{2-4}$ It may also present without prior or concurrent leukemia, referred to as 'aleukemic leukemia cutis'. ${ }^{5-7}$ This presentation provides the greatest diagnostic challenge, requiring careful histologic and cytologic evaluation for myeloid differentiation, coupled with appropriate interpretation of a carefully selected immunohistochemical panel.

\section{Case report}

An 87-year-old woman presented with a two-week history of erythematous papules with central crust on her arms, legs and upper chest. She described them as mildly pruritic and denied any prior history of similar lesions. Her past medical history was significant for hypothyroidism and hyperlipidemia. There was no recent change in her medications. Clinically, an arthropod assault or pyoderma gangrenosum was suspected. A 4-mm punch biopsy was performed on a representative lesion from the left anterior thigh.

The biopsy revealed a superficial atypical infiltrate of the papillary and reticular dermis with a predominantly perivascular, but somewhat interstitial distribution pattern (Fig. 1A, B). A grenz zone was noted 
(A)

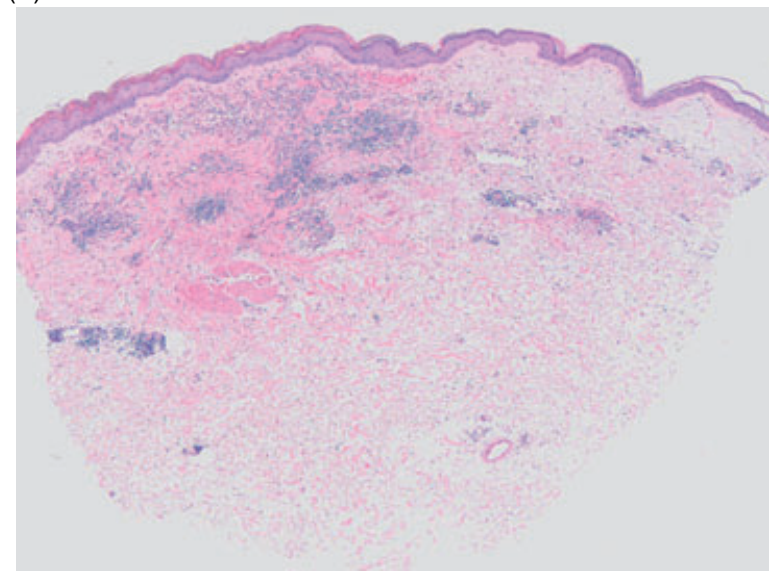

(B)

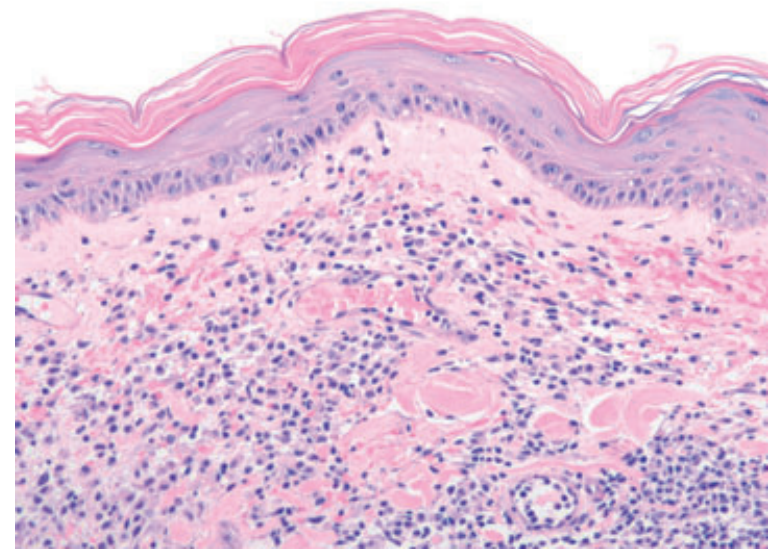

Fig. 1. (A) A superficial perivascular and interstitial infiltrate of the papillary and reticular dermis was present $(\mathrm{H} \& \mathrm{E}$ stain, $\times 20$ magnification). (B) Evidence of a grenz zone was noted above an atypical superficial infiltrate (H\&E stain, $\times 200$ magnification).

above the infiltrate. Cytophagocytosis was focally noted throughout the lesion (Fig 2A, B). The atypical cells were reactive for lysozyme, CD43, CD68, CD117 and S-100 protein (Fig. 3). Immunohistochemical stains to CD34, CDla, myeloperoxidase, CD79a and CD20 were nonreactive in the cells in question. A reactive T-cell population was highlighted with CD3. Special stains for infectious agents, including PAS, GMS and Gram stain, were negative for microorganisms and fungus. Based on the histologic and immunophenotypic features, a diagnosis of myeloid LC was rendered.

Peripheral blood studies, a bone marrow biopsy, flow cytometry and molecular studies were subsequently performed. The patient was found to have a normocytic anemia (hemoglobin $11.1 \mathrm{~g} / \mathrm{dl}$; mean corpuscular volume of $88.8 \mathrm{fl}$ ) and thrombocytopenia (platelets $89 \mathrm{~K} / \mu \mathrm{l}$ ). A complete blood count revealed an elevated white blood cell count of $22.21 \mathrm{~K} / \mu \mathrm{l}$ with a differential of $36 \%$ blasts, $24 \%$ neutrophils, 19\%
(A)

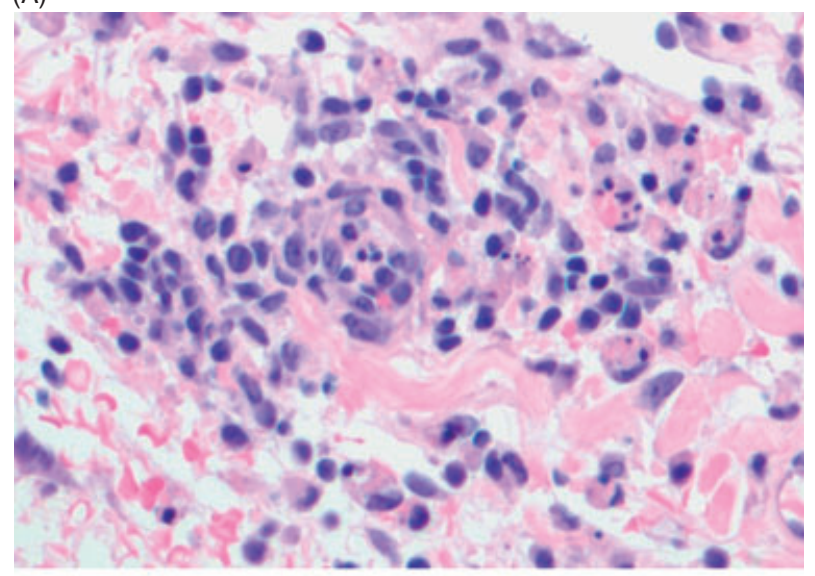

(B)

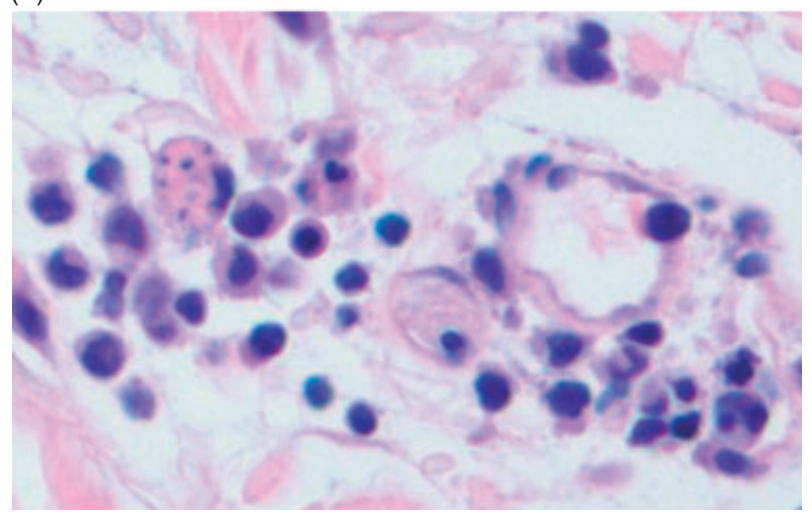

Fig. 2. (A \& B) Photomicrograph of a representative skin papule showing atypical cells and the presence of cytophagocytosis (H\&E stain, $\times 400$ magnification).

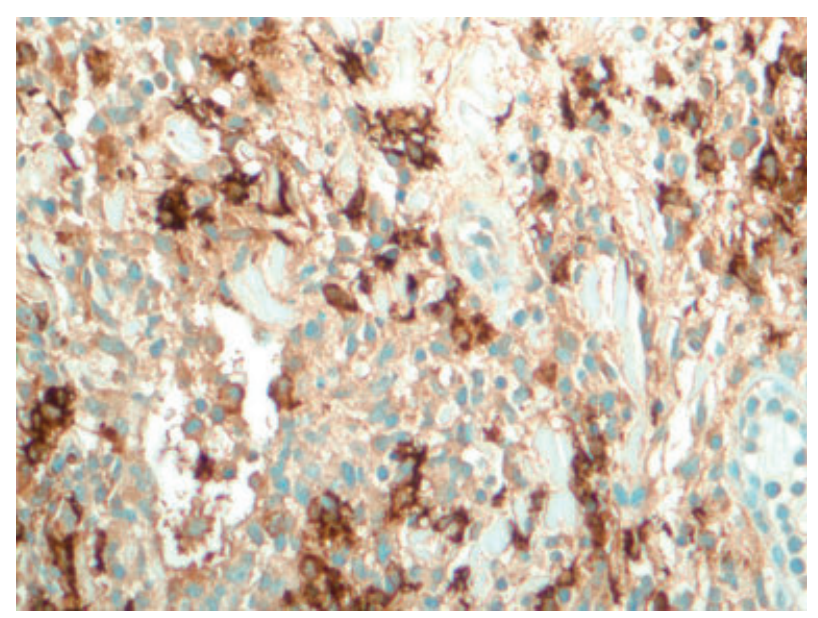

Fig. 3. Immunohistochemistry demonstrated expression of S-100 protein by the atypical myelomonocytic cells (S100-protein, $\times 400$ magnification).

monocytes, 10\% myelocytes, 5\% metamyelocytes, $2 \%$ promyelocytes and $1 \%$ lymphocytes. The bone marrow biopsy revealed hypercellular bone marrow (80\% cellularity) with sheets of immature, atypical and 
Thomas et al.

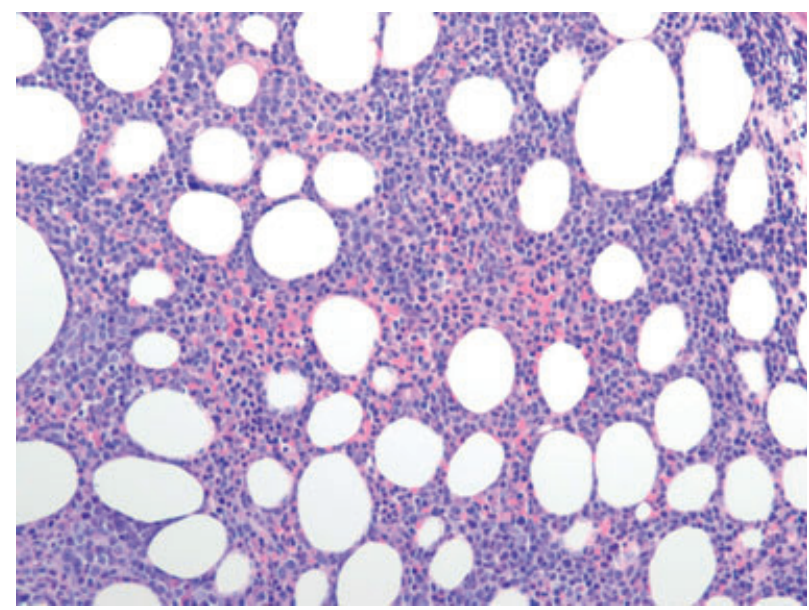

Fig. 4. Bone marrow evaluation demonstrated hypercellularity with sheets of atypical, primitive myeloid cells (H\&E stain, $\times 200$ magnification).

mononuclear cells (Fig. 4). Four-color flow cytometric immunophenotypic studies revealed a population of myeloid blasts that represented $45 \%$ of the analyzed events. Fluorescent in situ hybridization studies for a translocation of the MLL gene on chromosome 11 were negative, and cytogenetic studies showed a normal female karyotype. The histologic, cytogenetic and immunophenotypic characteristics were those of an acute myelomonocytic leukemia.

\section{Discussion}

Myeloid LC is the cutaneous involvement of leukemic cells consisting of myeloblasts and other myeloid precursors. Leukemic infiltration of the skin producing a solitary lesion may also be referred to as myeloid sarcoma or extramedullary myeloid tumor. Other terms that have been employed in the past include granulocytic sarcoma, chloroma, myeloblastoma, myelocytoma, granulocytic leukosarcoma and chloromyeloma. 6,8 The term chloroma originated secondary to the green color occasionally seen on gross examination, attributable to the presence of the intracellular enzyme myeloperoxidase. ${ }^{9}$

LC has a diverse range of clinical presentations and may present as erythematous macules, papules, plaques, nodules or ulcerative lesions, with a predilection for the lower extremities followed by the upper extremities, trunk and face. ${ }^{6,10,11}$ Myeloid LC shows a bimodal age distribution, most commonly occurring in patients younger than 15 years of age and between 45 and 55 years of age. ${ }^{8}$ The incidence of cutaneous involvement occurring in association with leukemia has been reported to be $5 \%$ to $15 \%$ in adults and up to $30 \%$ in children. ${ }^{11}$ Myeloid leukemia showing monocytic differentiation more frequently involves the skin than other types of myeloid leukemia. ${ }^{12}$ Leukemia patients with a $\mathrm{t}(8 ; 12)$ chromosomal translocation or numerical abnormalities of chromosome 8 , particularly trisomy 8, also appear to have an increased incidence of cutaneous involvement. ${ }^{3,6,13,14}$ A de novo occurrence or 'aleukemic leukemia cutis' has been described in which no overt hematologic disorder is evident at presentation. ${ }^{5,6}$ However, most patients presenting with aleukemic leukemia cutis develop AML within 1 year. $^{15,16}$

The histologic features of myeloid LC are variable, and a high index of suspicion is usually necessary to make the correct diagnosis. Helpful diagnostic features are presented in Table 1. A misdiagnosis rate of up to $75 \%$ has been reported in the literature. ${ }^{17}$ Most cases are initially given the diagnosis of nonHodgkin lymphoma, mycosis fungoides, metastatic undifferentiated carcinoma, Burkitt lymphoma or large cell lymphoma. 1,16,18,19 The histologic pattern varies depending on the density of the infiltrate. A dense infiltrate usually presents with either a diffuse or nodular and diffuse pattern with frequent extension into the subcutaneous fat. ${ }^{20,21}$ In the setting of a sparse infiltrate, the tumor cells are typically confined to the dermis and are predominantly perivascular or periappendageal in location. ${ }^{22}$ Most cases show a well-demarcated grenz zone and absence of epidermal involvement, although one study showed single or multiple foci of intraepidermal spread in more than one-third of cases. ${ }^{16}$ However, extensive epidermotropism is usually not appreciated and when present should raise the suspicion of mycosis fungoides. Other histologic features that may be seen in LC include the presence of single tumor cells intercalating between collagen bundles, Langerhans type giant cells, leukemic vasculitis and focal necrosis. ${ }^{23-27}$

Cytologic features evolve along a spectrum according to the degree of maturation of the leukemic cells: differentiated, immature or blastic. Differentiated lesions are composed predominantly of promyelocytes and mature neutrophils, whereas immature lesions are primarily composed of promyelocytes and myeloblasts. Blastic and immature leukemic cell infiltrates often resemble large cell lymphomas. ${ }^{1}$ Although the sensitivity is less than $50 \%$, when present, eosinophilic precursors known as eosinophilic myelocytes, characterized by their large violaceous granules, may serve as an important clue to the diagnosis of myeloid LC. ${ }^{6,17,28}$ Ancillary ultrastructural studies may prove helpful if electron dense granules are present within the tumor. ${ }^{29}$

Immunohistochemical analysis is mandatory in the evaluation of LC. CD45 (leukocyte common antigen) is expressed in approximately $90 \%$ of 
Table 1. Diagnostically helpful features of myeloid leukemia cutis

\begin{tabular}{|c|c|}
\hline Evaluation of leukemia cutis (LC) & Features \\
\hline Gross examination & $\begin{array}{l}\text { - Pale green color of tissue owing to the presence of myeloperoxidase (diminished } \\
\text { if received in fixative). }{ }^{29} \\
\text { - Red fluorescence with exposure to UV light. }{ }^{6}\end{array}$ \\
\hline Histology & $\begin{array}{l}\text { - Diffuse or nodular and diffuse dermal infiltrate. } \\
\text { - Presence of grenz zone. }{ }^{16,20,23} \\
\text { - Frequent extension into the subcutaneous adipose tissue. }{ }^{20,21} \\
\text { - Perivascular and/or periappendageal distribution. }{ }^{22,23} \\
\text { - Atypical cells infiltrating between collagen fibers. }{ }^{23,27} \\
\text { - Focal necrosis, Langerhans' type giant cells and leukemic vasculitis. }{ }^{24-26}\end{array}$ \\
\hline Cytology & $\begin{array}{l}\text { - Presence of eosinophilic myelocytes (eosinophilic precursors with large } \\
\text { eosinophilic and basophilic granules) is a clue to the diagnosis., }{ }^{6,17,28} \\
\text { - Mitotic figures are usually present. } \\
\text { - Varies with leukemic cell differentiation: }{ }^{1} \\
\text { - Differentiated: variable cell sizes, lobulated nuclei, some cells with eosinophilic } \\
\text { granularity. } \\
\text { - Immature: majority of cells with irregular vesicular nuclei and nucleoli. } \\
\text { Blastic: monotonous, medium to large-sized cells with inconspicuous nuclei, } \\
\text { fine powdery chromatin, and scanty cytoplasm. }\end{array}$ \\
\hline Immunohistochemistry & $\begin{array}{l}\text { - CD45 (leukocyte common antigen) positive in } 90 \% \text { of cases. } .^{19} \\
\text { - Lysozyme and CD43 are sensitive markers for myeloid LC. } .^{1,3,4,29,30} \\
\text { - Chloroacetate-esterase and myeloperoxidase stains also sensitive, but more } \\
\text { dependent on cellular differentiation. }{ }^{1} \\
\text { - CD117 (c-Kit) reactivity seen in } 85 \% \text { of myeloid LC. }{ }^{31} \\
\text { - CD68 may provide utility in more differentiated lesions. } .^{3,4,12} \\
\text { - Variable staining with Mac387, CD34 and CD56. }{ }^{30}\end{array}$ \\
\hline Ultrastructural & $\begin{array}{l}\text { - Electron dense granules (most notably ellipsoidal granules) containing axial } \\
\text { crystals. }{ }^{29}\end{array}$ \\
\hline
\end{tabular}

cases of myeloid LC, and when positive, helps to exclude non-hematopoietic neoplasms from the differential diagnosis. ${ }^{19}$ Ritter et al. compared the immunohistochemical profiles of cases of cutaneous involvement by myeloid leukemia to cases of peripheral T-cell lymphoma and found that CD34 and Mac 387 were specific, but relatively insensitive, markers of LG. ${ }^{30}$ Menasce et al. examined 26 cases of extramedullary involvement of myeloid leukemia and found that the staining pattern varied according to the degree of maturation of the neoplastic cells. Chloroacetate-esterase, myeloperoxidase and CD15 were expressed in the majority of welldifferentiated lesions and a smaller proportion of poorly differentiated or blastic lesions. Lysozyme and CD43 were the most sensitive markers with expression in $25(96 \%)$ and $26(100 \%)$ of the cases, respectively. The authors suggested an immunohistochemical panel that included lysozyme, CD43, chloroacetate-esterase and myeloperoxidase, along with $\mathrm{B}$ and $\mathrm{T}$ lymphocyte markers (CD3 and CD79a or CD20), to confirm the diagnosis of myeloid LG. ${ }^{1}$ Others have recommended the addition of CD68, a marker of macrophage origin, and CD117, a transmembrane tyrosine kinase receptor, to this panel when myeloid LC is a diagnostic consideration. ${ }^{3,4,12,31}$
The expression of S-100 protein in myeloid $\mathrm{LC}$, as found in our case, has been previously reported in the literature. ${ }^{29} \mathrm{~S}-100$ protein is a calcium-binding protein which has been detected in a variety of neoplastic and nonneoplastic tissues, including central and peripheral nervous system cells, melanocytes and Langerhans cells. ${ }^{23}$ Elliott et al. evaluated 10 cases of myeloid sarcoma for S-100 protein expression, five of which presented as aleukemic leukemia cutis. The authors demonstrated weak to strong S-100 protein immunoreactivity in six cases $(6 / 10) \cdot{ }^{29}$ Kaiserling et al. studied 16 skin biopsy specimens with leukemic infiltrates and found the majority expressed S-100 protein. They went on to hypothesize that this expression represented leukemic cells that had undergone differentiation. ${ }^{23}$

Cytophagocytosis is a phenomenon of active phagocytosis of leukocytes, erythrocytes and platelets. In the dermatology literature, cytophagocytosis is classically associated with the diagnosis of so-called cytophagic histiocytic panniculitis, now regarded as subcutaneous panniculitis-like T-cell lymphoma (SPTCL), characterized histologically as panniculitis with 'bean bag cells', i.e. large histiocytes containing fragmented leukocytes. ${ }^{32}$ Cytophagocytosis by histiocytes appears to be related to the production of cytokines, particularly interferons and macrophage 
inflammatory protein $1 \alpha$, produced by endothelial cells, lymphocytes and macrophages themselves. The phagocytic nature shown by blast cells in AMLs might be explained by the 'monocytic' differentiation of the cell population; this hypothesis is supported by the increased association of this finding in AML of the myelomonocytic and monocytic types. ${ }^{33} \mathrm{In}$ addition, the presence of cytophagocytosis by blast cells in AMLs has also been shown to have prognostic significance. Liso et al. evaluated bone marrow and peripheral blood smears of 1138 cases of AML for the presence of cytophagocytosis. One percent of the AML cases showed cytophagocytosis, and these patients had poor clinical outcomes, including diminished responses to therapy and shorter survival times, in comparison to those cases without this histologic feature. ${ }^{33,34}$ These findings suggest that the presence of cytophagocytosis may provide prognostic relevance in addition to aiding in the diagnosis of malignancy.

The combination of cytophagocytosis and S-100 protein reactive cells may generate the consideration of Rosai-Dorfman disease (sinus histiocytosis with massive lymphadenopathy) within the differential diagnosis. Cutaneous involvement of Rosai-Dorfman disease is characterized by foamy histiocytes, some of which show emperipolesis, in a background of a dense mixed infiltrate consisting of lymphocytes, plasma cells and neutrophils. Emperipolesis differs from cytophagocytosis in that the phagocytosed cells are not digested by enzymes and are morphologically well preserved within the histiocytes. In addition, the characteristic histiocytic cells show diffuse, strong cytoplasmic and nuclear staining for S-100 protein. CD68 and lysozyme have been shown in a percentage of Rosai-Dorfman cells as well. ${ }^{35}$ However, a pure cutaneous involvement of Rosai-Dorfman disease is rare as most patients have evidence of systemic involvement, facilitating in the differentiation from LC.

The prognosis of patients with myeloid LC has been shown to correlate with the initial presentation. The overall outcome in patients with AML prior to the development of LC does not appear adversely impacted by a subsequent diagnosis of LC. However, patients without AML at the time of diagnosis of LC tend to have a worse prognosis. ${ }^{6}$ In addition, correct initial diagnosis of LC at presentation has been found to impact patient prognosis. Mansi et al. found that patients diagnosed correctly at the time of presentation and treated with AML protocols had remissions lasting from 2 to 166 months, whereas patients initially misdiagnosed were less likely to have a period of remission. 36
In conclusion, myeloid LC can be a difficult diagnosis when associated with an aleukemic presentation and unexpected histologic and immunohistochemical findings. The diagnosis of LC is often made in retrospect once leukemia becomes present clinically. Careful evaluation of clinical, gross and histologic findings along with employment of an appropriate immunohistochemical panel may aide in the correct diagnosis of LC at the time of initial presentation.

\section{References}

1. Menasce LP, Banerjee SS, Beckett E, Harris M. Extra-medullary myeloid tumour (granulocytic sarcoma) is often misdiagnosed: a study of 26 cases. Histopathology 1999; 34: 391.

2. Raja V, Bryant B, Bessman DJ, Alperin JB. Soft tissue sarcomas. Case 1. Granulocytic sarcoma: presentation with nodal and skin involvement. J Clin Oncol 2004; 22: 2026.

3. Alexiev BA, Wang W, Ning Y, et al. Myeloid sarcomas: a histologic, immunohistochemical, and cytogenetic study. Diagn Pathol 2007; 2: 42.

4. Ratnam KV, Su WP, Ziesmer SC, Li CY. Value of immunohistochemistry in the diagnosis of leukemia cutis: study of 54 cases using paraffin-section markers. J Cutan Pathol 1992; 19: 193.

5. Ohno S, Yokoo T, Ohta M, et al. Aleukemic leukemia cutis. J Am Acad Dermatol 1990; 22: 374.

6. Sisack MJ, Dunsmore K, Sidhu-Malik N. Granulocytic sarcoma in the absence of myeloid leukemia. J Am Acad Dermatol 1997; 37: 308 .

7. Hejmadi RK, Thompson D, Shah F, Naresh KN. Cutaneous presentation of aleukemic monoblastic leukemia cutis a case report and review of literature with focus on immunohistochemistry. J Cutan Pathol. 2008; 35: 46.

8. Pulsoni A, Falcucci P, Anghel G, et al. Isolated granulocytic sarcoma of the skin in an elderly patient: good response to treatment with local radiotherapy and low-dose methotrexate. J Eur Acad Dermatol Venereol 2000; 14: 216.

9. Youssef AH, Zanetto U, Kaur MR, Chan SY. Granulocytic sarcoma (leukaemia cutis) in association with basal cell carcinoma. BrJ Dermatol 2006; 154: 201.

10. Su WP, Buechner SA, Li CY. Clinicopathologic correlations in leukemia cutis. J Am Acad Dermatol 1984; 11: 121.

11. Cho-Vega JH, Medeiros LJ, Prieto VG, Vega F. Leukemia cutis. Am J Clin Pathol 2008; 129: 130.

12. Cibull TL, Thomas AB, O'Malley DP, Billings SD. Myeloid leukemia cutis: a histologic and immunohistochemical review. J Cutan Pathol 2008; 35: 180.

13. Abe R, Umezu H, Uchida T, et al. Myeloblastoma with an $8 ; 21$ chromosome translocation in acute myeloblastic leukemia. Cancer 1986; 58: 1260.

14. Agis H, Weltermann A, Fonatsch C, et al. A comparative study on demographic, hematological, and cytogenetic findings and prognosis in acute myeloid leukemia with and without leukemia cutis. Ann Hematol 2002; 81: 90.

15. Rekha A, Ravi A, Thanka J, Kuruvilla S. Chronic lower limb ulcer? No-chloroma! Int J Low Extrem Wounds 2003; 2: 168.

16. Longacre TA, Smoller BR. Leukemia cutis. Analysis of 50 biopsy-proven cases with an emphasis on occurrence in myelodysplastic syndromes. Am J Clin Pathol 1993; 100: 276. 
17. Neiman RS, Barcos M, Berard C, et al. Granulocytic sarcoma: a clinicopathologic study of 61 biopsied cases. Cancer 1981; 48: 1426.

18. Beswick SJ, Jones EL, Mahendra P, Marsden JR. Chloroma (aleukaemic leukaemia cutis) initially diagnosed as cutaneous lymphoma. Clin Exp Dermatol 2002; 27: 272.

19. de Arruda Camara VM, Morais JC, Portugal R, da Silva Carneiro SC, Ramos-e-Silva M. Cutaneous granulocytic sarcoma in myelodysplastic syndrome. J Cutan Pathol 2008; 35: 876

20. Sun NC, Ellis R. Granulocytic sarcoma of the skin. Arch Dermatol 1980; 116: 800.

21. Geyer AS, Gill M, Husain S, Fox LP, Grossman ME. Subcutaneous myeloid sarcoma. Arch Dermatol 2005; 141: 104.

22. Sepp N, Radaszkiewicz T, Meijer CJ, et al. Specific skin manifestations in acute leukemia with monocytic differentiation. A morphologic and immunohistochemical study of 11 cases. Cancer 1993; 71: 124.

23. Kaiserling E, Horny HP, Geerts ML, Schmid U. Skin involvement in myelogenous leukemia: morphologic and immunophenotypic heterogeneity of skin infiltrates. Mod Pathol 1994; 7: 771 .

24. Baksh FK, Nathan D, Richardson W, Kestenbaum T, Woodroof J. Leukemia cutis with prominent giant cell reaction. Am J Dermatopathol 1998; 20(1): 48.

25. Jones D, Dorfman DM, Barnhill RL, Granter SR. Leukemic vasculitis: a feature of leukemia cutis in some patients. Am J Clin Pathol 1997; 107: 637.

26. Smoller BR. Leukemic vasculitis: a newly described pattern of cutaneous involvement. Am J Clin Pathol 1997; 107: 627.
27. Trizna Z, TschenJ, Natelson EA. Multiple subcutaneous nodules on the torso and leg. Leukemia cutis. Arch Dermatol 1998; 134: 1479 .

28. Davey FR, Olson S, Kurec AS, Eastman-Abaya R, Gottlieb AJ, Mason DY. The immunophenotyping of extramedullary myeloid cell tumors in paraffin-embedded tissue sections. Am J Surg Pathol 1988; 12: 699.

29. Elliott CJ, McCarthy KP, Carter RL, Davies P. Granulocytic sarcoma: misleading immunohistological staining with MT1 and S100 protein antibodies. J Clin Pathol. 1989; 42: 188.

30. RitterJH, Goldstein NS, Argenyi Z, Wick MR. Granulocytic sarcoma: an immunohistologic comparison with peripheral T-cell lymphoma in paraffin sections. J Cutan Pathol 1994; 21: 207.

31. Chen J, Yanuck RR, 3rd, Abbondanzo SL, Chu WS, Aguilera NS. c-Kit (CD117) reactivity in extramedullary myeloid tumor/granulocytic sarcoma. Arch Pathol Lab Med 2001; 125: 1448 .

32. Wick MR, Patterson JW. Cytophagic histiocytic panniculitis-a critical reappraisal. Arch Dermatol 2000; 136: 922.

33. Liso V, Specchia G, Capalbo S, Laricchia R, Magno M. Cytophagocytosis by the blast cells in acute myeloid leukemia. Leuk Lymphoma 1995; 18: 65.

34. Powell BL, McNay JW, Brown S, Cooper MR, Pettenati MJ. Translocation $(8 ; 16)(\mathrm{p} 11 ; \mathrm{p} 13)$ in patients with acute monocytic leukemias. An evolving syndrome? Cancer Genet Cytogenet 1988; 36: 109.

35. Kong YY, Kong JC, Shi DR, et al. Cutaneous rosai-dorfman disease: a clinical and histopathologic study of 25 cases in China. Am J Surg Pathol 2007; 31: 341.

36. Mansi JL, Selby PJ, Carter RL, Powles RL, McElwain TJ. Granulocytic sarcoma: a diagnosis to be considered in unusual lymphoma syndromes. Postgrad Med J 1987; 63: 447. 